\title{
Bringing experiential learning into the lecture theatre using
}

\section{D printed objects [version 1; peer review: 2 approved with}

\section{reservations]}

\section{David P. Smith}

School of Bioscience and Chemistry, Sheffield Hallam University, Sheffield, UK
V1 First published: 13 Jan 2016, 5:61

https://doi.org/10.12688/f1000research.7632.1

Latest published: 03 Jun 2016, 5:61

https://doi.org/10.12688/f1000research.7632.2

\section{Abstract}

The ability to conceptualize 3D shapes is central to understanding biological processes. The concept that the structure of a biological molecule leads to function is a core principle of the biochemical field. Conceptual teaching usually involves vocal explanations or using two dimensional slides or video presentations. A deeper understanding may be obtained by the handling of objects. 3D printed biological molecules can be used as active learning tools to stimulate engagement in large group lectures. These models can be used to build upon initial core knowledge which can be delivered in either a flipped form or a more didatic manner. Within the teaching session the students are able to learn by handling, rotating and viewing the objects to gain an appreciation of an enzyme's active site or the structure of DNA for example. Models and other artefacts are handled in small groups and act as a focus for talking points to generate conversation. Through this approach core knowledge is first established and then supplemented with high level problem solving through a "Think-Pair-Share" cooperative learning strategy. The teaching delivery is adjusted based around experiential learning activities by moving the object from mental cognition and into a physical environment leading to student engagement in the lecture theatre and a dialog with the lecturer. The use of artefacts in teaching allows the lecturer to create interactive sessions that challenge and enable the student. This approach can be applied at all levels and across many disciplines.

\section{Keywords}

3D printing , Active Learning , Experiental Learning , Higher Education , Biomolecules

\section{Open Peer Review}

Approval Status

1 2

\section{version 2}

(revision)

03 Jun 2016

version 1

13 Jan 2016

$\begin{array}{cc} & \\ \text { view } & \text { view } \\ ? & ? \\ \text { view } & \text { view }\end{array}$

1. Richard Bowater, University of East Anglia,

Norwich, UK

2. Carola Bruna, University of Concepción,

Concepción, Chile

Any reports and responses or comments on the article can be found at the end of the article. 
This article is included in the Innovations and

$\hat{\Gamma} \mathrm{SEB}$

best practices in undergraduate education

collection.

Corresponding author: David P. Smith (d.p.smith@shu.ac.uk)

Competing interests: No competing interests were disclosed.

Grant information: This work was funded by the Department of Bioscience and Chemistry, Sheffield Hallam Universty, Sheffield, S1

1WB.

The funders had no role in study design, data collection and analysis, decision to publish, or preparation of the manuscript.

Copyright: ( 2016 Smith DP. This is an open access article distributed under the terms of the Creative Commons Attribution License, which permits unrestricted use, distribution, and reproduction in any medium, provided the original work is properly cited.

How to cite this article: Smith DP. Bringing experiential learning into the lecture theatre using 3D printed objects [version 1; peer review: 2 approved with reservations] F1000Research 2016, 5:61 https://doi.org/10.12688/f1000research.7632.1

First published: 13 Jan 2016, 5:61 https://doi.org/10.12688/f1000research.7632.1 


\section{Introduction}

Ability to conceptualize 3D shapes is central to the understanding of biological processes. The dogma that the structure of biological molecules leads to function is central to biochemical understanding and is a core principle of the field. For example how the binding site of enzymes catalyses a reaction or how the major groove of DNA allows specific interactions with transcription factors. Understanding of such concepts is often a requirement for accreditation by learned bodies such as the Society of Biology, 2013 and the Institute of Biomedical Science, 2010 (https://www.ibms.org/go/ qualifications/ibms-courses/accreditation). Grounding in these concepts is often undertaken during the first year of study on the undergraduate courses within core modules in large group teaching environments. Students arrive with a range of experiences and prior knowledge ranging from the basic to more in-depth understanding of these topics.

Eysenck (2012) explains that within the teaching space students are required to imagine what would happen if an object was rotated or altered in a process known as "mental rotation". Although some students have the ability to picture 3D objects in their minds, this is not true for all. Even at higher levels fellow researchers have stated that they "can't conceptualise protein shapes in my mind".

Traditionally the knowledge required to understand 3D structure and related concepts have been presented through the use of PowerPoint slides; slides which are often heavy in text. PowerPoint slides represent objects two dimensionally and this is useful for detailing core knowledge. This approach however does not help the students develop more complex cognitive $3 \mathrm{D}$ mental rotation skills (Nigel, 2014). There is a danger that the activities are perceived to be content driven by using a two dimensional approach in which the students remain passive observers throughout the session. This approach affords a more superficial engagement with the subject, potentially promoting 'surface learning' behaviour, leading to poorer understanding (Biggs, 1999). This behaviourist approach has its merits under certain conditions such as when a large amount of content needs to be covered in a short amount of time (Woolfolk, 2009). However, this approach is restricted to the acquisition and learning of knowledge and can prevent access to higher tiers of learning (Anderson \& Krathwohl, 2000; Bloom, 1956). An alternative to this approach is the inclusion of active learning in teaching sessions whereby students become involved in the learning and are engaged in activities leading to higher order thinking (analysis, synthesis, evaluation) (Bonwell, 1991). Presented here is one such approach where students handle physical 3D printed objects within a teaching setting.

\section{Methodology}

Within the research setting physical structural models of molecules have long-been used to help understand function. Models of the protein in question are often generated and handled in small group meetings as talking points to generate new hypotheses. This approach was adapted to large group teaching sessions with cohorts of 150 students in a standard tiered lecture theatre. Sessions using the models were delivered twice to the same students on their first year of study. Once in their first semester and once in the second semester of a two semester core Biochemistry module. The models have also been used in second year teaching when discussing DNA binding proteins within a Molecular Biology module. To encourage students to become engaged in the learning existing sessions were adapted to deliver base level learning supplemented with high level problem solving through the use of 3D printed models. The $3 \mathrm{D}$ printed molecules in question were linked to the core content and act as a focal point for learning. Models where created from the protein data bank (PDB) code 2LYZ (Lysozyme) and B-form of DNA was taken from the now defunct Glactone Pedagogical PDB collection. The PDB file was modified by the removal of the water molecules and the surface of the molecule was calculated in a molecular graphics program (Visual Molecular Dynamics 1.8.5). PDB files are also included as Supplementary material 1 and Supplementary material 2 . The resulting files where rendered in a standard STL format using the (STL Plugin, Version 2.0) which is compatible with CAD and most 3D printers. STL files are also included as Supplementary material 3 and Supplementary material 4. Models used here were produced on a fused deposition modeling (FDM) Dimension sst 768 rapid prototyping 3D printer (Figure 1) and were approximately $2 \times 2 \times 4 \mathrm{~cm}$. Paper based stereo images were also provided in the same session. The use of the $3 \mathrm{D}$ projection images also allowed the students to review and reflect on the learning at a later date and gave a focal point and prompt for later revision (Figure 2).

Sessions were structured so that taught content prepared the students for the experiential learning activities by first establishing core knowledge. This content gave the students the vocabulary to later describe the objects they would handle. The taught content laid foundation knowledge relating to how molecules such as enzymes perform reactions and to gain an appreciation of the structure of DNA. The active learning component was then included to placing the object out from mental cognition and into a physical environment. This was achieved by allowing the students to rotate and view objects physically through the handling of $3 \mathrm{D}$ printed models of these biomolecules. The overall teaching style follows a simplified form of Kolb's experiential learning cycle (Kolb, 1984). This model

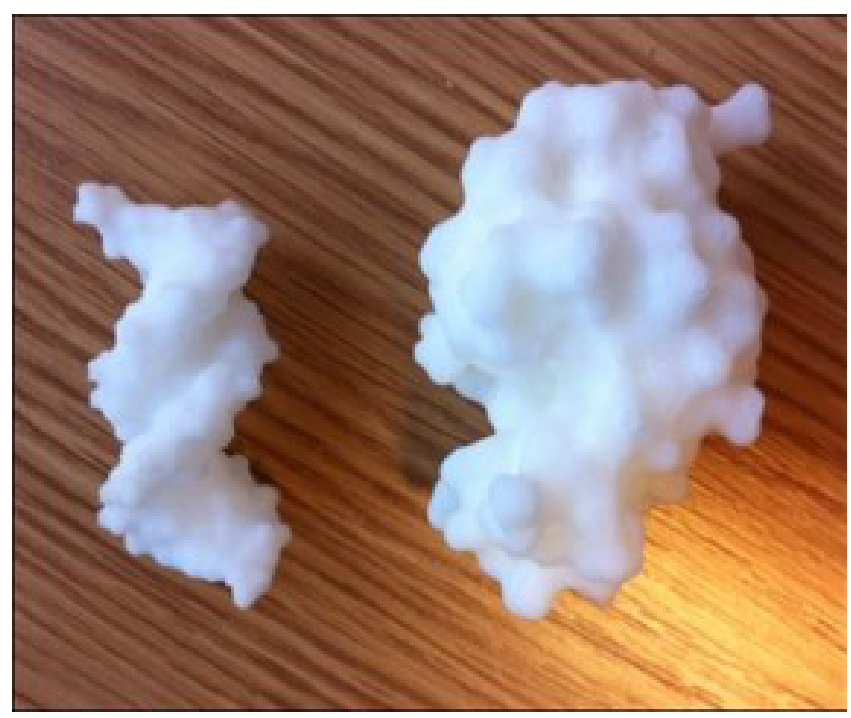

Figure 1. 3D printed models. B-form DNA (right) and the enzyme lysozyme PDB: 2LYZ (left) used within the teaching session. 

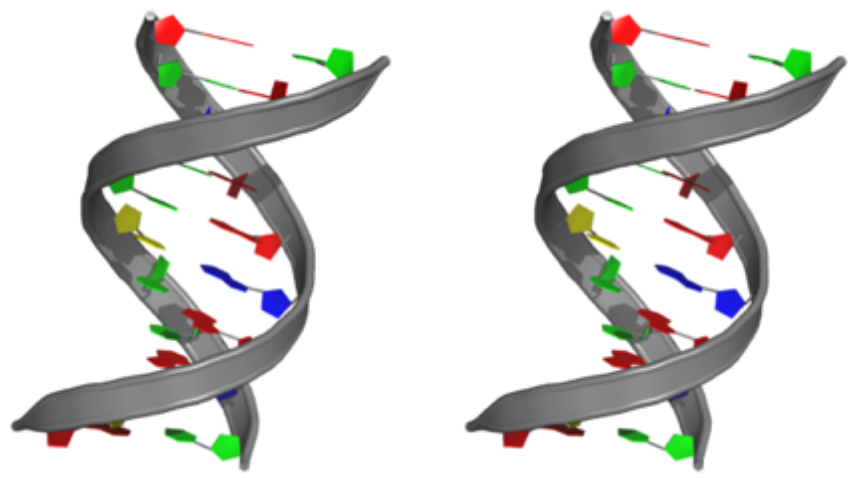

Figure 2. Handout example. Cross eye stereo image: Instruction to students were gaze at the stereo pair, keeping your eyes level (don't tilt your head left or right), and cross your eyes slightly so that the two images in the center come together. When they converge or fuse, you will see them as a single 3D image.

is well-established in science based learning. As teachers and learners we are able to jump onto the cycle at any point but in order for it to be useful the stages must be followed in sequence. Learning can then be applied in new situations and subsequently built upon.

\section{Thinking (abstract conceptualization)}

New concepts were introduced through the use of slides, videos and written material. A range of media animations, web-based content and strong links to core texts were used. The "thinking" section of the lesson plan had prepared the students to identify key features of the models they would later handle.

\section{Doing (active experimentation)}

In order to develop a 3D understanding of biomolecules students were asked to handle printed models and apply their new knowledge and concepts through self-directed small group discussions (Figure 3). Questioning was centred on those features they could observe and was objective, such as: What do they feel like? What general shape do they have? What features can you observe? This encouraged student interaction as there was no wrong answers to the questions as it was personal observation.

\section{Feeling (concrete experience)}

Through this approach core knowledge is first established which is then supplemented with high level problem solving through "ThinkPair-Share" cooperative learning strategies. Students are asked to think through questioning about an aspect of the object and discuss the answers with each other. Questions were asked that probed understanding, such as what are those bumps on the surface? What is the function of that groove? As such, learning is enhanced through the opportunities to elaborate on the ideas through conversation. I observed that this approach led to increased student engagement in the lecture theatre as the students are willing to talk with each other and the lecturer as confidence in their understanding increased.

\section{Reflective observation}

Finally the students are given time and encouraged to write on handouts in their own words the key points and note theories

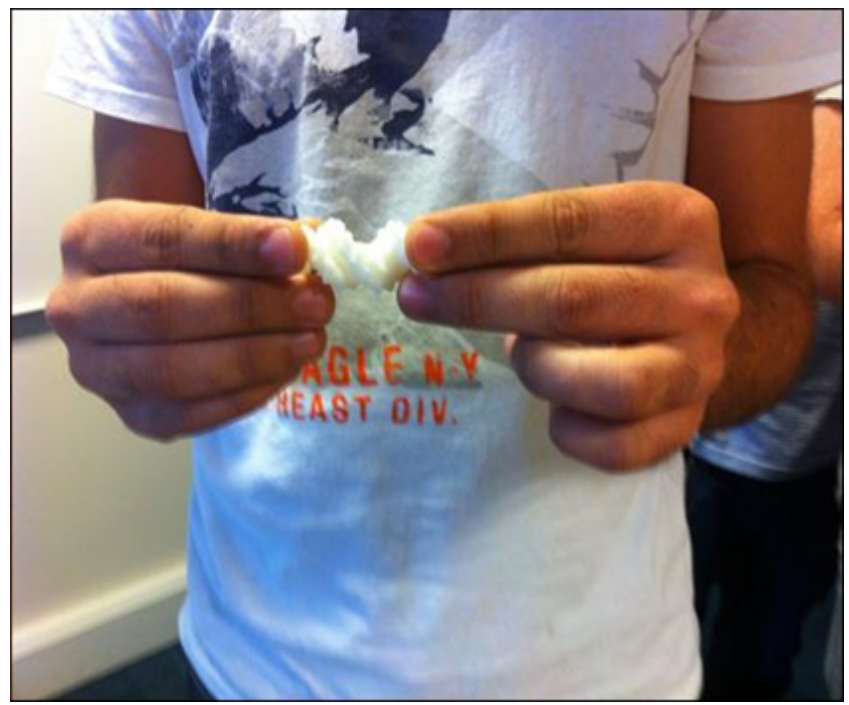

Figure 3. Photograph. Students handle the 3D printed molecules and were asked to identify structural features.

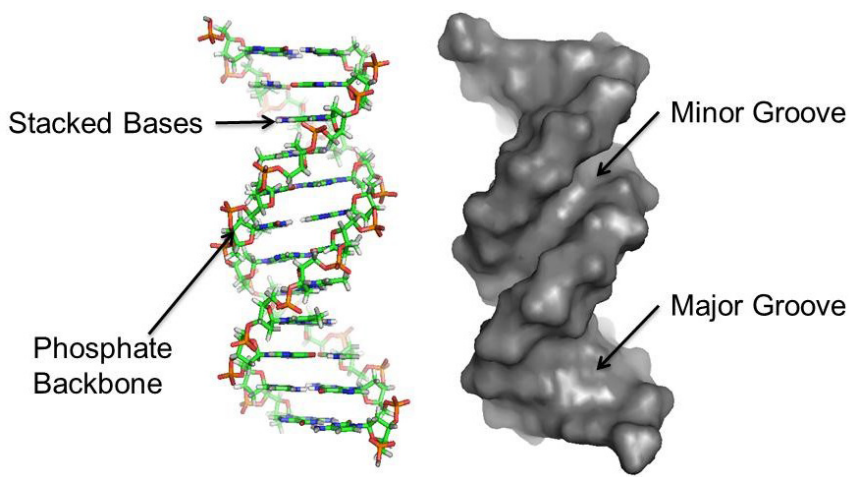

Figure 4. Handout example. Handouts where designed that allowed the students to identify key features of the molecule in question and complete a question sheet. This ensured key learning objectives were recorded.

that have been discussed. (Figure 4). The handouts were structured such that the key learning objectives were recorded (handouts used can be found in Supplementary material 5). For example, students were asked to identify key features of the molecule in question and complete a question sheet where they were asked to identify structural features. In order for the students to take ownership of the knowledge, they discussed specific situations for how this information is used in practice. Examples where given from a researchinformed context and were tailored to be course specific.

\section{Conclusion}

Access to 3D printing technology is becoming more wide spread as the costs associated with the technology drop and most institutes already have access to such printers. Active learning approaches are becoming increasing common place as teaching staff move away from didactic strategies (DesLauriers et al., 2011; Seery, 2015; Sharples et al., 2014). 
The use of objects within the classroom is one such approach and, in evaluations conducted with my own students, they identify them as both engaging and informative. Students describe helpful visual aids such as "scale models" and "engaging lectures" with reference to previously produced 3D printed models. The students engage with the models which stimulate conversation rather than distract attention.

The use of objects, therefore, can be seen as a focal point for conversation and suggests there are similar applications to enhance other areas of teaching. Peers within the nursing team at my own university have considered the use of dolls as talking points for their students to support discussions about empathy. Such abstract learning environments dealing with relationships rather than facts and thinking situations in symbolic form can be pictured as an area of conceptual knowledge (Anderson \& Krathwohl, 2000). Objects have also been used by peers in analytical chemistry teaching where parts of instruments help to develop understanding into drug detection when taken to the lecture theatre.
The use of artefacts in teaching opens new ways to challenge students. Teachers can create interactive sessions that challenge students to see artefacts through the lenses of mathematics, science, language, arts, and social studies. While the use of objects in both large and small group teaching is currently under researched and under reported, it has the potential to increase student engagement by facilitating active learning methods.

\section{Competing interests}

No competing interests were disclosed.

\section{Grant information}

This work was funded by the Department of Bioscience and Chemistry, Sheffield Hallam University, Sheffield, S1 1WB.

I confirm that the funders had no role in study design, data collection and analysis, decision to publish, or preparation of the manuscript.

\section{Supplementary material}

Supplementary material 1: Lysozyme PDB file. The file "2LYZ no water.pdb" contains the atomic coordinates of the enzyme Lysozyme with the crystallographic water molecules removed from the file. The file originated was sourced from the PDB file 2LYZ.

Click here to access the data.

Supplementary material 2: B-form DNA PDB file. The file "bdna.pdb" contains the atomic coordinates of B-form DNA used to create the DNA model structure and hand-out images. The file originated from the now defunct Glactone Pedagogical PDB collection.

Click here to access the data.

Supplementary material 3: Lysozyme STL file. The file "lysozyme.stl" contain surface renderings of lysozyme and was used to create the 3D printed model shown in Figure 1. The files is in a standard STL (STereoLithography) format native to the stereolithography CAD software created by 3D Systems. This file format is supported by many software packages and is widely used for rapid prototyping and 3D printing.

Click here to access the data.

Supplementary material 4: B-form DNA STL file. "B-DNA2.stl" contain surface renderings of B-form DNA and was used to create the 3D printed model shown in Figure 1. The files is in a standard STL (STereoLithography) format native to the stereolithography CAD software created by 3D Systems. This file format is supported by many software packages and is widely used for rapid prototyping and 3D printing.

Click here to access the data.

Supplementary material 5: Hand-outs used to allow students to record their experiences and notes from the session.

Click here to access the data. 
Anderson LW, Krathwohl DR: A Taxonomy for Learning, Teaching, and Assessing: A Revision of Bloom's Taxonomy of Educational Objectives. Allyn \& Bacon. 2000.

Biggs J: Teaching for quality learning at university. Buckingham: Society for Research into Higher Education and Open University Press. 1999.

Bloom BS (ed.): Taxonomy of Educational Objectives: the classification of educational goals. Handbook I: Cognitive Domain. New York: McKay. 1956.

Reference Source

Bonwell CC, Eison JA: Active learning: Creating excitement in the classroom ASHE-ERIC Higher Education Report No. 1. Washington DC: The George Washington University. 1991.

Reference Source

Deslauriers L, Schelew E, Wieman C: Improved learning in a large-enrollment physics class. Science. 2011; 332(6031): 862-864

PubMed Abstract | Publisher Full Text

Eysenck MW: Fundamentals of cognition. Psychology, Hove. 2012.

Reference Source

Institute of Biomedical Science: Criteria and Requirements for the Accreditation and Re-accreditation of BSc (Hons) degrees in Biomedical Science. 2010;
[Accessed: 28th July 2014].

Reference Source

Kolb D: Experiential learning: experience as the source of learning and development. Englewood Cliffs, New Jersey: Prentice Hall. 1984.

Reference Source

Nigel JT: "Mental Imagery". The Stanford Encyclopedia of Philosophy. Edward N. Zalta (ed.). 2014.

Reference Source

Seery MK: Flipped learning in higher education chemistry: emerging trends and potential directions. Chem Educ Res Pract. 2015; 16: 758-768.

Publisher Full Text

Sharples M, Adams A, Ferguson R, et al.: Innovating Pedagogy 2014: Open University Innovation Report 3. Milton Keynes: The Open University. 2014. Reference Source

Society of Biology: Handbook for the Society of Biology's Degree Accreditation Programme. 2013; [Accessed: 28th July 2014]

Reference Source

Woolfolk A: Educational Psychology: Eleventh Edition. Prentice Hall. 2009.

Reference Source 


\section{Open Peer Review}

\section{Current Peer Review Status: ? ?}

\section{Version 1}

Reviewer Report 14 March 2016

https://doi.org/10.5256/f1000research.8219.r12885

(C) 2016 Bruna C. This is an open access peer review report distributed under the terms of the Creative Commons Attribution License, which permits unrestricted use, distribution, and reproduction in any medium, provided the original work is properly cited.

\section{Carola Bruna \\ Faculty of Biological Sciences, University of Concepción, Concepción, Chile}

This article presents a pedagogical experience in which 3D printed objects were used to promote the understanding of biochemistry concepts in two student-centred interactive sessions within a course. The design is based in the advances and availability of 3D printing technology and the importance of conceptualizing three-dimensional structure in order to understand biochemistry core concepts such as the relationship between the structure and function of proteins.

3D printing technology is in fact becoming increasingly accessible and it is contributing and changing many fields. Undoubtedly, education should benefit from this technology, probably many teachers are thinking about it, including myself. Thus, experiences on how to implement it in class are interesting and valuable. In this sense, this work can contribute with relevant information. Nevertheless, some aspects need to be addressed, clarified or discussed further so that weaknesses and strengths are identified, which will allow replicating or improving the shared experience. In this context, the following suggestions could improve this manuscript:

Title: The work is more than using 3D printed objects, it is student-centred education, interactive and motivating and specially thought to address a problem in science, to enable visualization of abstract concepts, specifically in Biochemistry.

The author state that 3D structures and related problems have been presented with slides. Many teachers also use 3D visualization programs, combining theoretical and computer laboratory sessions. Differences, advantages and disadvantages between these two approaches could be discussed.

The experience should be described further. What was actually done? Why were those structures chosen? Which were the concepts students were expected to learn in each session? What were the related learning outcomes? How many groups? How many molecules? Was the discussion tutored? If it was, how many tutors participated? The models seem very small, what were the structural features they had to identify mentioned in figure 3? Costs? 
As this experience was justified as a mean for conceptualizing 3D shapes for understanding Biochemistry, other reported experiences using molecules should be discussed and compared. For example: "The effect of student manipulation of molecular models on chemistry achievement according to Piagetian level" or "Using three-dimensional models to teach molecular structures in high school chemistry". I am sure there are more examples, maybe even in biochemistry.

The main weakness of this work is that no assessment of the approach is included. I understand that it is very difficult to assess learning gain, and that the intention of the author is modest, in the sense that this article is intended to share an experience instead of researching education. However, at least the perception of the students should have been included. This would at least suggest the strongest aspects and allowed identifying possible improvements. If the intervention is recent and there still contact with the students, there is still a possibility to conduct an online survey. If that is not the case, at least the author should comment further regarding the perception of the teacher: Did the students seem motivated? Did they participate more actively than in other activities? Did they comment informally positive aspects? Another approach could be to analyze exams answers regarding the concepts that were studied in these special sessions and compared them to those of the previous year.

Despite the previous comments, I still consider that sharing this experience is valuable to the community. In this work, I particularly appreciate that the activity was implemented in a large course using a standard classroom, with no additional requirements. If the main suggestions could be addressed, I believe it would be appropriate for indexing as published in F1000Research.

Competing Interests: No competing interests were disclosed.

I confirm that I have read this submission and believe that I have an appropriate level of expertise to confirm that it is of an acceptable scientific standard, however I have significant reservations, as outlined above.

Author Response 12 May 2016

David Smith, Sheffield Hallam University, Sheffield, UK

Thank you for your comments and by addressing them I hope the manuscript has been improved. In the response below I have set out the changes made. Some off the comments made are reflected by referee 2 and the response below is applicable to both referees.

Comment - However, there is no evaluation of whether the approach is successful or cost-effective and, thus, readers cannot easily judge if they should consider it in their own teaching environment.

The cost per model was around $£ 7$ when purchased internally which covered materials. The models have now been used over four years in two different streams (Biology and Chemistry). There 20 models were produced with a total cost of $£ 140$. This is less than the printing cost of the handouts for the same session. 
Comment - There is a comment that the author "observed that this approach led to increased student engagement in the lecture theatre as the students are willing to talk with each other and the lecturer as confidence in their understanding increased", but there is no direct feedback from students involved in the sessions.

On the advice of the reviewer the perception of the students was assessed via a written questionnaire. Students in their final year of study were asked to reflect on the use of the models during their past learning. 44 students were questioned and 35 remembered using the models. 32 of these responded with positive comments and 3 with neutral comments. Of the 9 students who did not remember using the models many admitted to not having attended the lecture. The following text and supplementary information has now been added. In addition comments have been referred to in the discussion section.

Results

Students in their final year of study were asked to reflect on the use of the 3D printed models during their past learning. 44 students were asked "Did you find the models helpful, if so how?" through an anonymous survey. Of the 44 responses 35 remembered using the models and 32 of these responded with positive comments ( 3 with neutral comments). Of the 9 students who did not remember using the models many admitted to not having attended the lecture.

Some students commented on the benefits the models provided as a visual aid, they were very useful for highlighting the key lecture points as well as being a visual aid."

Student comments also highlighted the use of the models as a tool in understanding the key learning objectives,

"Very useful to help understand major and minor grooves", and

"Allowed us to visualise the major and minor groove of DNA, as well as the binding sites for enzyme".

The students also explained that the models provided an alternative way of presenting information,

"they gave a 3D better understanding of the 3D structure of the enzyme than a 2D computer image."

It was also noted that the models could be used to gain a sense of scale, for example, the difference in size between a ribosome and organelles. The full list of comments is included as supplementary information. During each of the sessions there was a high level of student engagement involving the students talking to each other and to the lecturer with the key learning points being recalled three years after the teaching session.

Comment -The article suggests that its approach would be of value to other disciplines. In fact, the use of artefacts and the potential to handle objects is frequently used within the arts and humanities, particularly in subjects that combine history and art. The benefits of such approaches have been well described in the pedagogical literature for these disciplines and this article would be improved if it provided a deeper review and analysis of such information.

The following text has been integrated into the introduction discussing object based learning theory. 
The handling of molecular models within teaching sessions can aid this mental rotation and the use of models falls within the theories of object based learning. This approach involves the active integration of objects into the learning environment (Chatterjee, 2015). Working with objects strengthens learning is the central proposition of object-based learning as, according to Romanek (2008), the sense of touch can lead to a more memorable learning experience. The use of museums artefacts in history, art and biology has been well explored and there are a number of parallels between the handling of objects within these disciplines. Object- based learning theory links student activity to meaning making by challenging the student to engage with and interrogate the object It represents a constructivist approach in which the students develop their knowledge and understanding though interaction (Chatterjee, 2015). While the teacher facilitates this learning, the students have to learn for themselves through their interaction with each other centred on the object (Hannan, 2013). This approach enables the student to explore processes and events related to the object and further link these observations to complex abstract ideas and concepts.

Findings from my study support Chatterjee's (2015) conclusion that the students gain real knowledge by being actively involved in the experience of handling the objects. It has been highlighted that object-based learning should be both mentally and physically stimulating through some form of problem solving or experimentation (Coffield, 2004) and this was achieved in this study by challenging the students to find the active site of Lysozyme or identify the region of DNA to which proteins bind.

While objects can be used to enhance learning, there are logistical and pedagogical barriers to implementing them. For example, Cain (2010) says the main barrier for the implementation in the biosciences within the lecture theatre is the change to the adoption of a more student-centred and open-ended activities. The use of models in teaching needs to expand the concepts as understood by students at a particular stage in their learning (Bent, 1984) There is a danger for example when discussing enzymes that concepts such as the lock and key model could be reinforced over an induced fit model. Such dangers should be at the forefront of the lectures mind when utilising these models.

Competing Interests: No competing interests were disclosed.

Reviewer Report 26 January 2016

https://doi.org/10.5256/f1000research.8219.r11937

(c) 2016 Bowater R. This is an open access peer review report distributed under the terms of the Creative Commons Attribution License, which permits unrestricted use, distribution, and reproduction in any medium, provided the original work is properly cited.

\section{Richard Bowater}

School of Biological Sciences, University of East Anglia, Norwich, UK 
This article provides a brief description of an attempt to introduce experiential learning into lectures in the biochemical sciences. As described below, the author highlights a fundamental aspect of the subject that some students struggle to understand fully and proposes an approach that aims to help students engage better with the topic and the issues involved.

Structures of biological molecules are critical to their function and this is a core principle that must be understood by all students of the field of biochemistry. Full appreciation of this link requires students to develop 3-dimensional knowledge of a molecule and relate this to its biochemical activities. These are challenging concepts to introduce to students, especially in large cohorts. This article describes a strategy that takes advantage of the increasing availability and cost effectiveness of 3D printers to prepare molecules that can be "handled" by the students. The 3D printed biological molecules are used as active learning tools to stimulate student engagement and a deeper understanding of the link between structure and biochemical function. The approach described in the article is that core knowledge should first be established through conventional teaching approaches. The teaching delivery is then supplemented by discussions among the students and lecturer about the printed molecules, allowing interrogation of its physical environment.

The article provides an appropriate discussion of a topic that is clearly challenging to inexperienced learners in the biochemical sciences and suggests an approach that goes beyond the conventional lecture. However, there is no evaluation of whether the approach is successful or cost-effective and, thus, readers cannot easily judge if they should consider it in their own teaching environment. There is a comment that the author "observed that this approach led to increased student engagement in the lecture theatre as the students are willing to talk with each other and the lecturer as confidence in their understanding increased", but there is no direct feedback from students involved in the sessions.

The article suggests that its approach would be of value to other disciplines. In fact, the use of artefacts and the potential to handle objects is frequently used within the arts and humanities, particularly in subjects that combine history and art. The benefits of such approaches have been well described in the pedagogical literature for these disciplines and this article would be improved if it provided a deeper review and analysis of such information.

To be of improved value to the biochemistry teaching community, this study needs to provide a much clearer hypothesis. What is (are) its fundamental aim(s) and how will its success be tested and evaluated? It would be beneficial if a study could be developed that tested whether inclusion of the printed molecules in teaching sessions led to improved biochemical understanding among the students involved. Clearly this could take a significant amount of time and effort and may be beyond the remit of the study that is described.

Whether or not it is possible to evaluate the success of the approach, there are a number of important details that would be useful to assist other educators in considering whether they should adopt the strategy. For example, how many molecules are needed for each group of student and what is the approximate cost of preparing the molecules? Is there any value in using the approach multiple times (with different molecules) within the same module or same cohort of students?

In relation to publication of this article, it is not clear that it has been submitted as the most 
appropriate type of article for F1000Research. The study has been submitted as an Observation Article and the guidelines to authors state that: "Observation Articles allow the description of a novel observation that may be unexpected, and possibly currently without explanation." It is not clear to me what details in the article are "unexpected" or "without explanation" - these points need to be made much clearer to the reader. In considering the different types of articles published within F1000Research, it seems that it may be more applicable as a Research Note.

The article is reasonably clear and well written, but there are some minor errors that should be corrected by careful proof-reading. The title could be improved by highlighting that it focuses on "biochemistry teaching".

In summary, this article describes an interesting but rather straight forward intervention to allow biochemistry students to gain a better appreciation of the link between molecular structure and function. The suggested approach makes good use of computer-based technologies that are becoming more accessible and it is thus likely to be of interest to a wide group of educators in the biosciences (and other disciplines). Unfortunately, the study does not present any evaluation of the effect of the approach on student learning or understanding. Such information should be obtained from further cohorts of students in order to enable other educators to consider the value in the approach.

Competing Interests: No competing interests were disclosed.

I confirm that I have read this submission and believe that I have an appropriate level of expertise to confirm that it is of an acceptable scientific standard, however I have significant reservations, as outlined above.

Author Response 12 May 2016

David Smith, Sheffield Hallam University, Sheffield, UK

Thank you for your comments and by addressing them I hope the manuscript has been improved. In the response below I have set out the changes made.

The work is more than using 3D printed objects, it is student-centred education, interactive and motivating and specially thought to address a problem in science, to enable visualization of abstract concepts, specifically in Biochemistry. Thank you for your suggestions and I have altered the title to reflect your comments. "Active learning in the lecture theatre using 3D printed objects to visualise abstract concepts."

Many teachers also use 3D visualization programs, combining theoretical and computer laboratory sessions. Differences, advantages and disadvantages between these two approaches could be discussed.

The use of computer based representations is now easily accessible via personal devices. There are a wide range of 3D visualisation programs available which enable molecular structures to be moved, altered, rotated and interrogated. Programs such as the Java based Jmol applet allow students to manipulate molecules and investigate their structures. There are also a range of free programs that allow students to visualise molecules on smart 
phones and tablets such as "Molecules" for Apple iOS and "ESmol" for Android devices. These programs offer many advantages such as ready access to the $>118500$ structures available in the protein data bank (PDB). However, their use as tool in large group teaching can be problematic as all students require access to a device. In addition providing technical support to 150 students across three different platforms within a lecture theatre can also be problematic. Molecular viewers do work very well in small group seminar or lab sessions where support can be given or devices can be provided. Students can be directed through a range of tasks and the molecules can be explored in greater depth (Harris, 2009). However, the tablet based applications lack the tactile aspect of physically handling the object in question and can prevent the abstract observations that generate the initial interactions. The models are also engaging and can be used by groups of people who have had little training, unlike the visualisation programs (Harris, 2009). The models also allow an ability to quickly make abstract observations for example the spiral nature of DNA or the large clefts on an enzyme. It is these abstract observations that stimulate the initial peer-to-peer conversations. This approach allows the students to remain engaged with the topic and revisit their observations after the teaching session. In a study in which 3D printed models were offered alongside a molecular imaging program the students tend to prefer the models when asked questions about molecular structure that required higher order thinking skills (Harris, 2008). The tactile nature of the models appears therefore to leads to a more lasting memory of the interaction (Hurman, 2006).

\section{The response to the following questions has been embedded directly into the text. What was actually done?}

Molecules were handed around the group by the lecturer. They were handed out starting at the end of each of the rows of students. The students were asked to pass the molecules around and handle them directly. Once most of the students had handled the objects they were encouraged to talk with their peers about their observations.

\section{Why were those structures chosen?}

The two structures were chosen as they these molecules are established as examples within the taught material on the course. DNA is central to molecular biology and an understanding of how other molecules such as transcription factors interact with it is a key learning point in the Biochemistry program. Lysozyme was chosen as its structure and function are well understood. It also has a defined active site in which the substrate has been modelled. The use of lysozyme also integrated well with the rest of the module. Its action on the lipid polysaccharides found on the cell wall of gram negative bacteria resulting in lysis allowed links to microbiology and protein purification. It also integrates well with a second year structural biology practical in which lysozyme can be induced to undergo change from an alpha / beta structure to the beta sheet rich structure of amyloid fibrils resulting in a loss of function.

\section{Which were the concepts students were expected to learn in each session?}

The main concepts that the students were expected to learn was that the structure of a molecule brings about its function and subsequent properties.

\section{What were the related learning outcomes?}

In the DNA sessions the main learning outcome was to understand the difference between the major and minor grove within the structure of DNA and how proteins interact with these groves. Within the lysozyme sessions the learning outcome was to be able to identify where an active site maybe located on a protein and how a substrate would interact with it. 


\section{How many groups?}

The session has been run twice a year for three consecutive years with 120 - 150 students being present at each session.

\section{How many molecules?}

Within each session 20 molecules were used.

Was the discussion tutored? If it was, how many tutors participated?

The sessions were run in a standard lecture theatre with one lecturer delivering the session.

The models seem very small, what were the structural features they had to identify mentioned in figure 3 ?

For the DNA molecule it was the major and minor grove. The models are scaled such that an index finger would fit into the major grove. In the case if the enzyme it was the active site located across the middle of the protein.

Costs?

$£ 7$ each for raw materials

As this experience was justified as a mean for conceptualizing 3D shapes for understanding Biochemistry, other reported experiences using molecules should be discussed and compared.

The following text has been added

The use of physical models as a learning tool have been used to depict molecular geometry in both biochemistry and chemistry (Dori, 2001). The benefit of these objects has been demonstrated in an analysis of visuospatial thinking in chemistry. In this study it was concluded that adept visual perception skills correlate with achievement. DNA and protein models assembled from coloured computer-printouts on transparency film sheets have also been demonstrated to aid students in grasping various aspects of biopolymers (Jittivadhna, 2010). Students who hold physical models in their hands gain a better understanding of molecular geometry, than they could achieve solely from viewing images on a printed page. It has been reported by both Herman (2006) and Bain (2006) that physical models that can be easily manipulated, can play an important role in capturing the interest of students and encouraging deeper sophisticated thinking (Bain, 2006). Additionally, the students gain a language for talking about the concepts in question and enhance their understanding of abstract concepts by handling models ( $\mathrm{Wu}, 2004)$.

The positive comments from students polled in this study, in which 3D printed models were rated as most useful, are echoed in a comparable study where a side-by-side comparisons of seven different learning tools were undertaken by students in an introductory biochemistry class (Roberts, 2005). In that study, the models were shown to have an important role in capturing the interest of the students and stimulated sophisticated questioning. The main difference between these observations and those presented here, relate to the learning environment. Within the side-by-side comparisons study, the core concepts were introduced in a lecture and the models were handled as part of a 3-wk laboratory in a group of twenty students, generating tangible learning gains were observed. In the study discussed here, however, 150 students were allowed to handle the models directly within the lecture environment. Handling the models aided the students in visualising the molecules demonstrating the applicability of this approach to large group teaching. Schönborn, (2006) states that the ability to visualise ideas is a key skill for all students and it is a key skill for biochemists who are often presented with a range of visual interpretation including drawings, images, dynamic visuals, animated visuals, multimedia, 
and virtual reality environments. The use of models has the potential to help students construct their own visualisation and understanding of these molecules as demonstrated by the student comments reported here.

The main weakness of this work is that no assessment of the approach is included. On the advice of both reviewers the perception of the students was assessed via a written questionnaire. Students in their final year of study were asked to reflect on the use of the models during their past learning. 44 students were questioned and 35 remembered using the models. 32 of these responded with positive comments and 3 with neutral comments. Of the 9 students who did not remember using the models many admitted to not having attended the lecture.

The following text and supplementary information has now been added. In addition comments have been referred to in the discussion section.

Results

Students in their final year of study were asked to reflect on the use of the 3D printed models during their past learning. 44 students were asked "Did you find the models helpful, if so how?" through an anonymous survey. Of the 44 responses 35 remembered using the models and 32 of these responded with positive comments ( 3 with neutral comments). Of the 9 students who did not remember using the models many admitted to not having attended the lecture.

Some students commented on the benefits the models provided as a visual aid, "they were very useful for highlighting the key lecture points as well as being a visual aid." Student comments also highlighted the use of the models as a tool in understanding the key learning objectives,

"Very useful to help understand major and minor grooves", and

"Allowed us to visualise the major and minor groove of DNA, as well as the binding sites for enzyme".

The students also explained that the models provided an alternative way of presenting information,

"they gave a 3D better understanding of the 3D structure of the enzyme than a 2D computer image."

It was also noted that the models could be used to gain a sense of scale, for example,s the difference in size between a ribosome and organelles. The full list of comments is included as supplementary information. During each of the sessions there was a high level of student engagement involving the students talking to each other and to the lecturer with the key learning points being recalled three years after the teaching session.

Did the students seem motivated?

Yes there was a high level of engagement during the sessions; the students were talking to each other and to the lecturer.

\section{Did they participate more actively than in other activities?}

The participation level was probably equivalent to other sessions. However I have noted that a range of activities within the sessions a good way to keep students motivated and engaged. Too much of any intervention can lead to disengagement as has been reported for flipped classroom approaches.

Did they comment informally positive aspects?

See above response 
Another approach could be to analyze exams answers regarding the concepts that were studied in these special sessions and compared them to those of the previous year.

Unfortunately we do not hold the exam scripts locally and so gaining access to this is not possible. However it will be built into further studies as it is a good suggestion.

Competing Interests: No competing interests were disclosed.

The benefits of publishing with F1000Research:

- Your article is published within days, with no editorial bias

- You can publish traditional articles, null/negative results, case reports, data notes and more

- The peer review process is transparent and collaborative

- Your article is indexed in PubMed after passing peer review

- Dedicated customer support at every stage

For pre-submission enquiries, contact research@f1000.com 